\title{
Effects of coir type on growth, phytochemical accumulation and antioxidant activity in spinach
}

Acta
Horticulturae
Home

Search

Authors: $\quad$ R.M.A. Machado, I. Alves-Pereira, R.M.A. Ferreira

Keywords: substrates, soilless culture systems, phenols, DPPH, FRAP, peroxidase

DOI: $\quad$ 10.17660/ActaHortic.2021.1305.2

\section{Abstract:}

The effects of four commercial substrates peat; and three coir types

(Cocopeat, coir-crush chips and coir-medium) on plant growth, leaf nutrient concentration, total phenols, ascorbic acid, antioxidant activity (FRAP and DPPH) and peroxidase activity were evaluated in spinach (Spinacia oleracea L. 'Manatee'). Soil blocked spinach seedlings (five seedlings per block) were transplanted (on 16 February 2017) into to Styrofoam planting boxes (100-cm long $\times 25-\mathrm{cm}$ wide $\times 10-\mathrm{cm}$ high) filled with $14 \mathrm{~L}$ of substrate. Each planting box was irrigated daily by drip and fertilised with a complete nutrient solution. The nitrate concentration and $\mathrm{pH}$ in drainage water were higher in coir-chips than the other substrates. Shoot dry weight, leaf area and yield (fresh yield) in cocopeat and coir-medium were similar than those obtained in peat. Leaf nutrient concentration for the most leaf nutrients in cocopeat and coir-medium did not differ from those observed in peat. Leaf blade ascorbic acid, total phenols, FRAP, DPPH and peroxidase activity were affected by substrate type. Leaf blade of plants grown in cocopeat presented the highest value of total phenols, high values of DPPH and ascorbic acid and the lowest value of the peroxidase activity. The findings of this research suggest that the spinach grown in the different coir types may have a longer shelf life than in peat.

- Article - full text (enhanced PDF format, 680751 bytes)

- Article sharing - repository deposits - copyright questions

- References

- How to cite this article

- Translate

$$
\begin{aligned}
& \text { Selecionar idioma } v \\
& \text { Tecnologia do Google Tradutor }
\end{aligned}
$$

Download Adobe Acrobat Reader (free software to read PDF files)

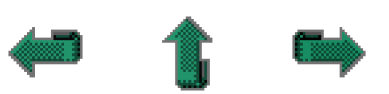


